\title{
A hybrid mechanistic-empirical approach to the modelling of twin screw feeders for continuous tablet manufacturing
}

Davide Bascone, ${ }^{* \dagger \dagger}$ Federico Galvanin, ${ }^{\ddagger}$ Nilay Shah, ${ }^{\dagger}$ and Salvador Garcia-Munoz

$1 \dagger$ Centre for Process System Engineering, Department of Chemical Engineering, Imperial College London, London, SW7 2AZ, United Kingdom

$\ddagger$ Centre for Process System Engineering, Department of Chemical Engineering, University College London (UCL), London, WC1E 6BT, United Kingdom

\Eli Lilly and Company, Lilly Research Laboratories, Indianapolis, Indiana, IN 46285, United States

E-mail: d.bascone@imperial.ac.uk

2 Introduction

3 Details on the physical properties and the parameters used in the simulations are provided

4 below. Further results from the model calibration and some sensitivity analyses are also 5 illustrated.

Powder properties 
Table 1: Physical properties of the bulk solids investigated. Acronyms used for bulk solids: $\mathrm{MCC}=$ MicroCrystalline Cellulose Avicel PH, CCS $=$ CrossCarmellose Sodium, $\mathrm{SSF}=$ Sodium Stearyl Fumarate. Physical properties: HR Hausner Ratio, FFc flow function coefficient, $\mathrm{d}_{32}$ mean diameter over surface (Sauter diameter), $\mathrm{d}_{43}$ mean diameter over volume, $\rho_{b}$ bulk density, $\delta$ effective angle of internal friction, $\phi$ angle of wall friction.

\begin{tabular}{lrrrrrrrrr} 
Bulk solid & $\begin{array}{r}\mathrm{HR} \\
{[-]}\end{array}$ & $\begin{array}{r}\mathrm{FFc} \\
{[-]}\end{array}$ & $\begin{array}{r}\mathrm{D}_{32} \\
{[\mu \mathrm{m}]}\end{array}$ & $\begin{array}{r}\mathrm{D}_{43} \\
{[\mu \mathrm{m}]}\end{array}$ & $\begin{array}{r}\rho_{b} \\
{\left[\mathrm{~kg} \mathrm{~m}^{-3}\right]}\end{array}$ & $\begin{array}{r}\text { Moisture } \\
{[\% \mathrm{w} / \mathrm{w}]}\end{array}$ & $\begin{array}{r}\text { Cohesion } \\
{[\mathrm{kPa}]}\end{array}$ & $\begin{array}{r}\delta \\
{\left[{ }^{\circ}\right]}\end{array}$ & $\begin{array}{r}\phi \\
{\left[{ }^{\circ}\right]}\end{array}$ \\
\hline Mannitol & 1.19 & 19.7 & 83.8 & 116.5 & 470 & $0.1^{1}$ & 0.13 & 37.7 & 12.3 \\
Lactose & 1.22 & 9.7 & 74.5 & 127.5 & 600 & $0.1^{1}$ & 0.29 & 48.5 & 27.0 \\
MCC 101 & 1.41 & 4.8 & 25.8 & 74.7 & 340 & $5.3^{1}$ & 0.16 & 46.0 & 44.8 \\
MCC 102 & 1.35 & 6.7 & 40.5 & 129.4 & 360 & $5.3^{1}$ & 0.15 & 44.5 & 43.9 \\
CCS & 1.38 & 7.0 & 18.3 & 58.0 & 520 & $11.3^{1}$ & 0 & $45.6^{3}$ & $40.2^{3}$ \\
SSF & 1.59 & 3.5 & 8.2 & 24.3 & 260 & $0^{2}$ & 0.27 & $48.2^{3}$ & $48.2^{3}$ \\
\hline
\end{tabular}

${ }^{1}$ Assuming an average relative humidity of $45 \%$, using GAB Eq. ${ }^{1}$.

2 Non-hygroscopic powder, moisture content neglected ${ }^{2}$.

${ }^{3}$ Estimated values for calculation purposes, assuming they vary linearly with FFc

\section{Friction coefficients}

Table 2: Estimated friction coefficients.

\begin{tabular}{lr} 
Bulk solid & $\mu$ \\
\hline Mannitol SD-100 & $0.81^{1}, 0.90^{2}$ \\
Lactose monohydrate & $0.85^{1}$ \\
Microcryst. cellulose PH 101 & $0.76^{1}$ \\
Microcryst. cellulose PH 102 & $0.77^{1}, 0.85^{2}$ \\
Crosscarmellose sodium & $0.80^{1}$ \\
Sodium stearyl fumarate & $0.73^{1}$ \\
\hline${ }^{1}$ Using feeder K-Tron KT20 & \\
${ }^{2}$ Using feeder K-Tron KT35 &
\end{tabular}


Table 3: Experiments used to calibrate and validate the model. Acronyms used for bulk solids: $\mathrm{MCC}=$ Microcrystalline Cellulose Avicel PH, CCS=Crosscarmellose Sodium, $\mathrm{SSF}=$ Sodium Stearyl Fumarate.

\begin{tabular}{lrrrr}
\hline Bulk solid & $\begin{array}{r}\text { Speed } \\
{[\mathrm{rpm}]}\end{array}$ & $\begin{array}{r}\text { Initial hopper load } \\
{[\mathrm{kg}]}\end{array}$ & Feeder & Used for \\
\hline Mannitol & 7.71 & 10.07 & K-Tron KT20 & Calibration \\
Mannitol & 19.20 & 18.81 & K-Tron KT35 & Calibration \\
Lactose & 77.10 & 4.79 & K-Tron KT20 & Calibration \\
MCC 101 & 38.50 & 1.35 & K-Tron KT20 & Calibration \\
MCC 102 & 77.10 & 8.99 & K-Tron KT20 & Calibration \\
MCC 102 & 38.40 & 17.78 & K-Tron KT35 & Calibration \\
CCS & 61.70 & 0.99 & K-Tron KT20 & Calibration \\
SSF & 61.70 & 1.20 & K-Tron KT20 & Calibration \\
Mannitol & 77.10 & 10.77 & K-Tron KT20 & Testing \\
Mannitol & 6.40 & 18.55 & K-Tron KT35 & Testing \\
Lactose & 7.71 & 1.08 & K-Tron KT20 & Testing \\
MCC 101 & 7.71 & 9.24 & K-Tron KT20 & Testing \\
MCC 102 & 7.71 & 8.33 & K-Tron KT20 & Testing \\
MCC 102 & 6.40 & 18.02 & K-Tron KT35 & Testing \\
CCS & 7.71 & 1.52 & K-Tron KT20 & Testing \\
SSF & 7.71 & 1.07 & K-Tron KT20 & Testing \\
\hline
\end{tabular}

\section{Calibration results}

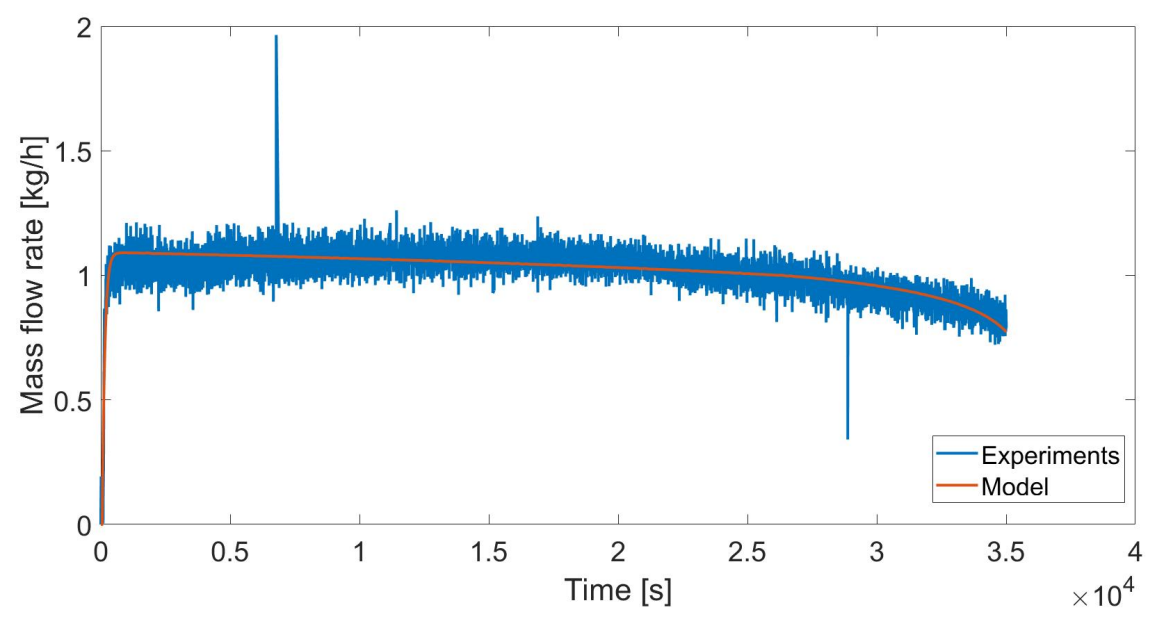

Figure 1: Model calibration using mannitol SD-100, feeder K-Tron KT20, screw speed 7.71 rpm. The blue line represents the measured values, the red line is the model response. 


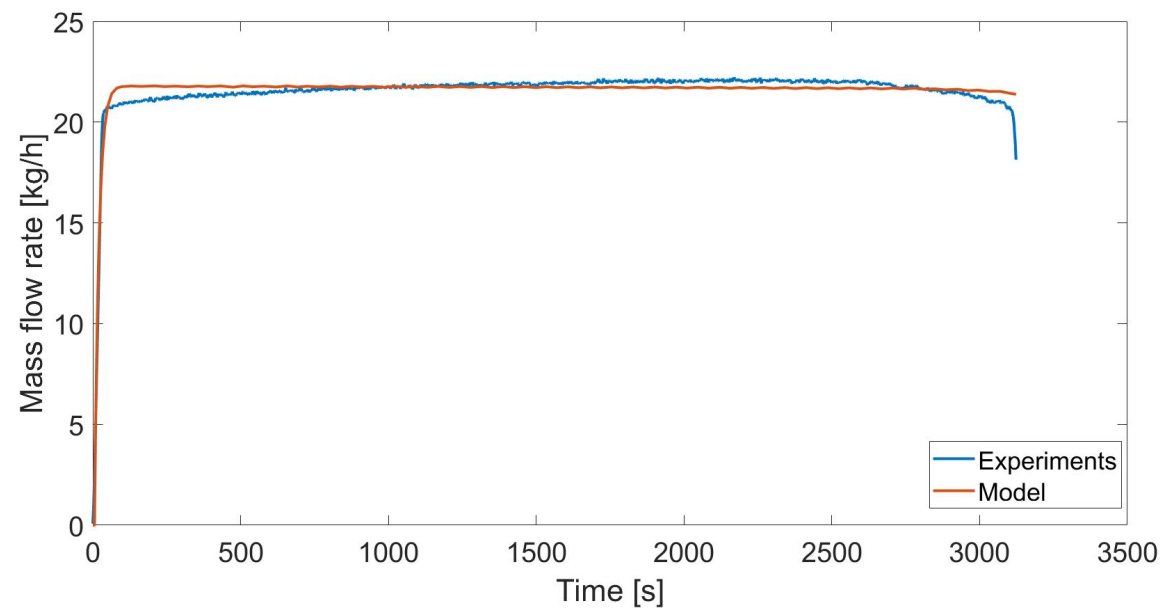

Figure 2: Model calibration using mannitol SD-100, feeder K-Tron KT35, screw speed 19.2 rpm. The blue line represents the measured values, the red line is the model response. 


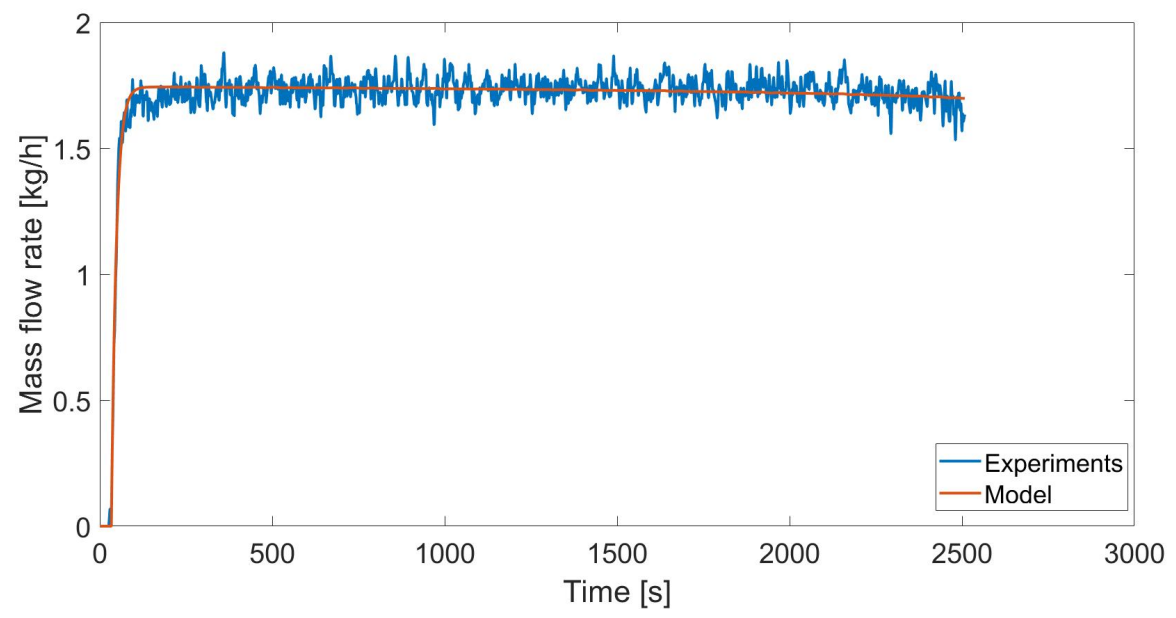

Figure 3: Model calibration using microcrystalline cellulose PH 101, feeder K-Tron KT20, screw speed $38.5 \mathrm{rpm}$. The blue line represents the measured values, the red line is the model response.

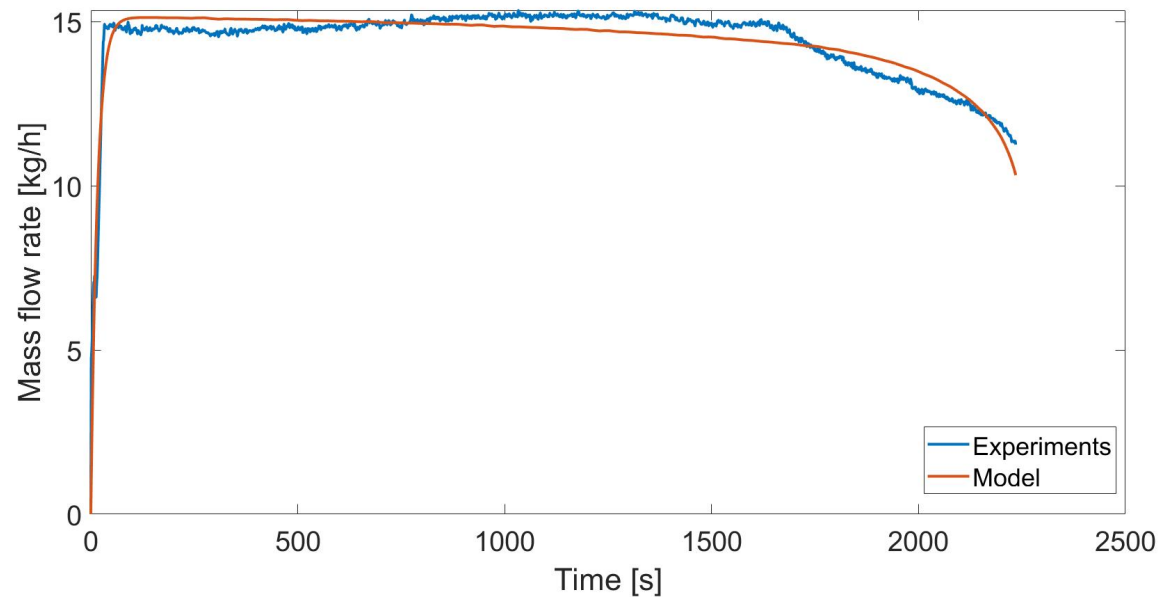

Figure 4: Model calibration using microcrystalline cellulose PH 102, feeder K-Tron KT20, screw speed $77.1 \mathrm{rpm}$. The blue line represents the measured values, the red line is the model response. 


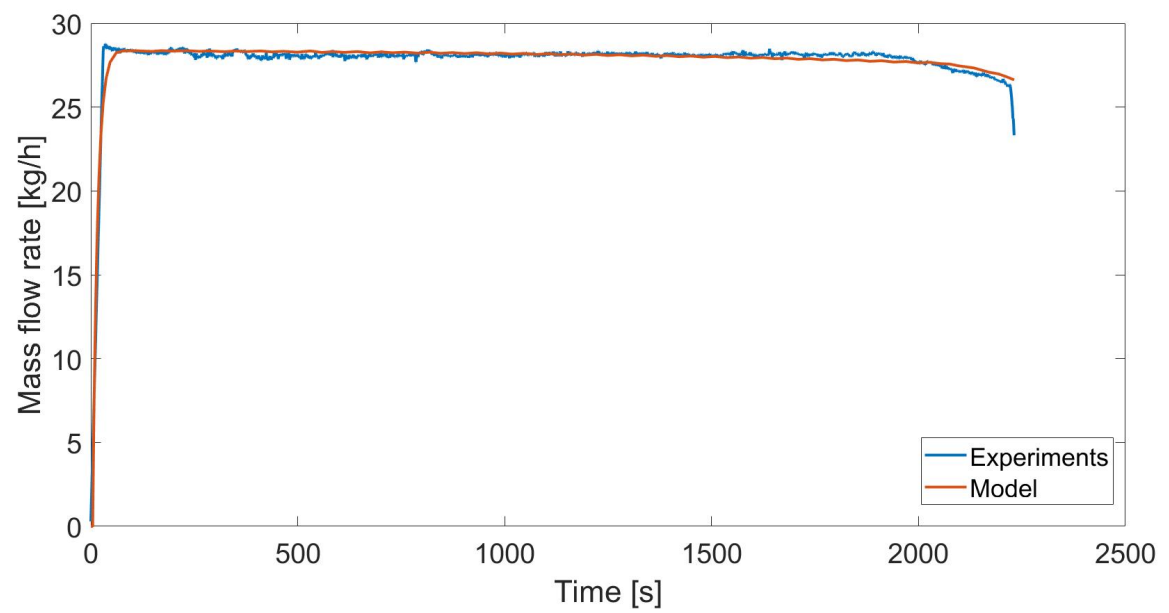

Figure 5: Model calibration using microcrystalline cellulose PH 102, feeder K-Tron KT35, screw speed $38.4 \mathrm{rpm}$. The blue line represents the measured values, the red line is the model response.

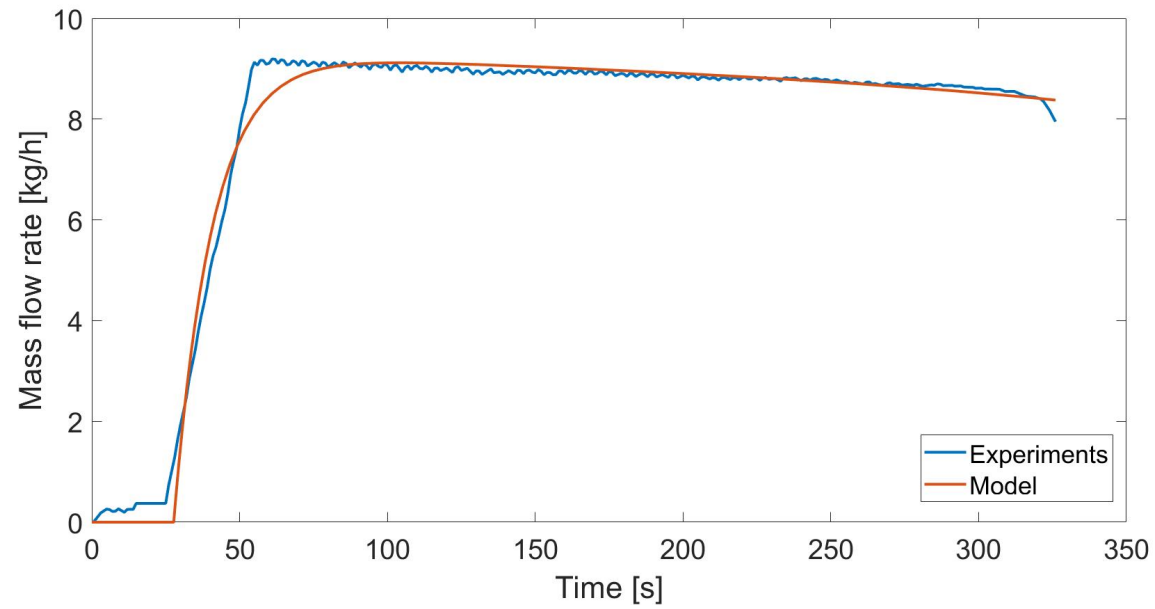

Figure 6: Model calibration using crosscarmellose sodium, feeder K-Tron KT20, screw speed $61.7 \mathrm{rpm}$. The blue line represents the measured values, the red line is the model response. 


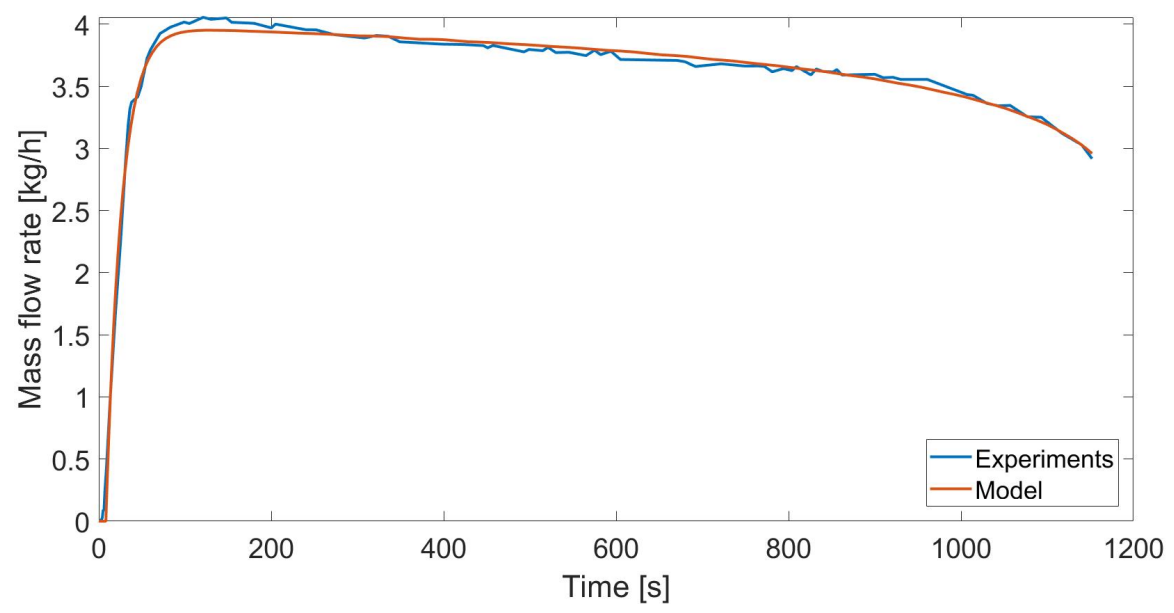

Figure 7: Model calibration using sodium stearyl fumarate, feeder K-Tron KT20, screw speed $61.7 \mathrm{rpm}$. The blue line represents the measured values, the red line is the model response.

\section{Sensitivity analyses}

Here, the effect of several parameters on the predicted feed rate is investigated. In particular, the impact of effective angle of internal friction, wall friction angle and switch point are illustrated.

The impacts of effective and wall friction angles on the predicted feed rates, for two different materials and different operating conditions, are shown below. Specifically, lactose monohydrate at $77.1 \mathrm{rpm}$ (Figures 8-9) and microcrystalline cellulose PH 101 at $7.7 \mathrm{rpm}$ (Figures 10-11) have been investigated. Simulations are carried out varying both angle of internal friction $\delta$ and wall friction angle $\phi$ up to $\pm 50 \%$ from the value measured by shear test (case of reference). Despite the significant changes in both friction angles, the effect on the feed rates is limited, with deviations from the case of reference lower than approximately $7 \%$ (for the highest $\delta$ using microcrystalline cellulose, deviation that decreases during time).

Finally, the impact of the switch point is investigated feeding mannitol at $77.1 \mathrm{rpm}$, using a cylindrical hopper (Figure 12), and feeding microcrystalline cellulose PH 102 at 6.4 rpm, using a conical hopper (Figure 13). Switch points above the highest position of the flow aid 


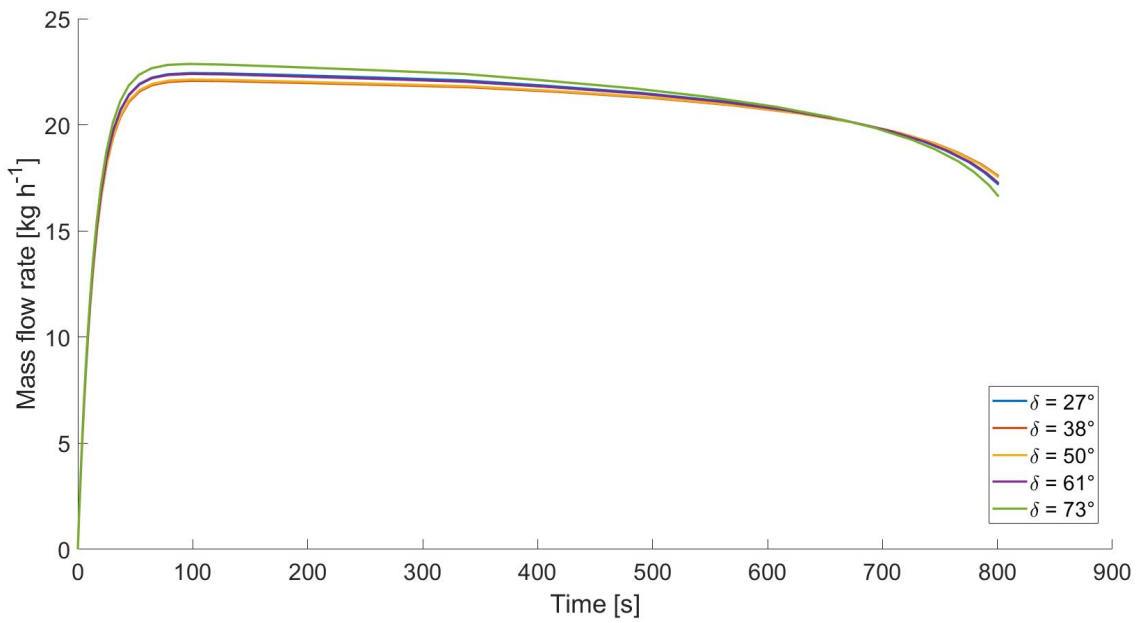

Figure 8: Impact of the effective angle of friction $\delta$ on the predicted feed rate using K-Tron KT20, lactose monohydrate, $77.1 \mathrm{rpm}$. 


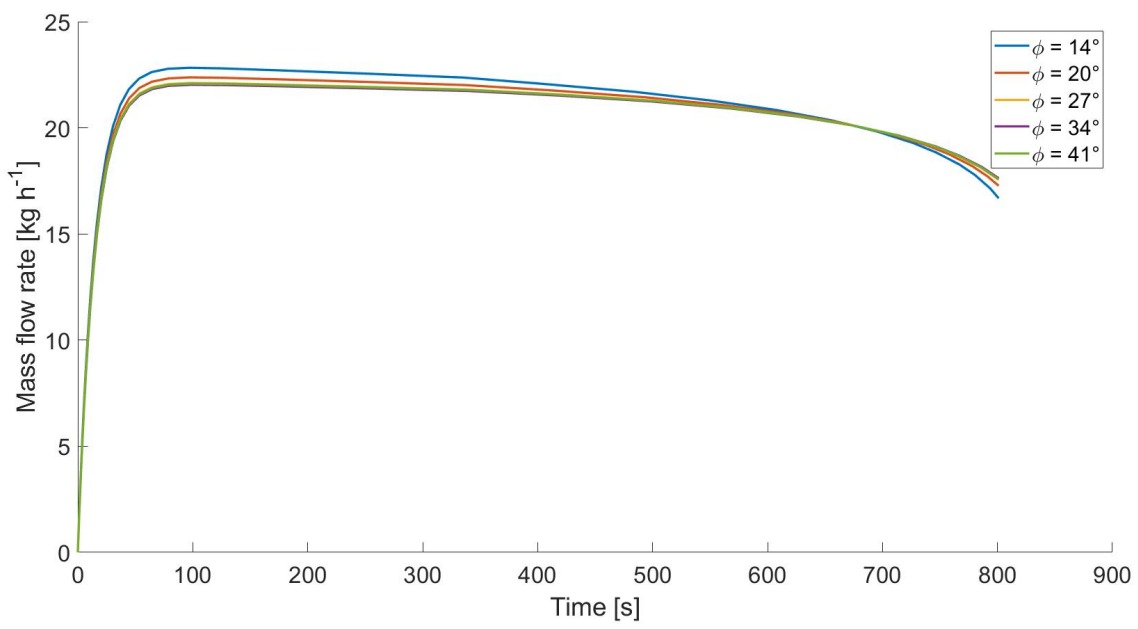

Figure 9: Impact of the wall friction angle $\phi$ on the predicted feed rate using K-Tron KT20, lactose monohydrate, $77.1 \mathrm{rpm}$.

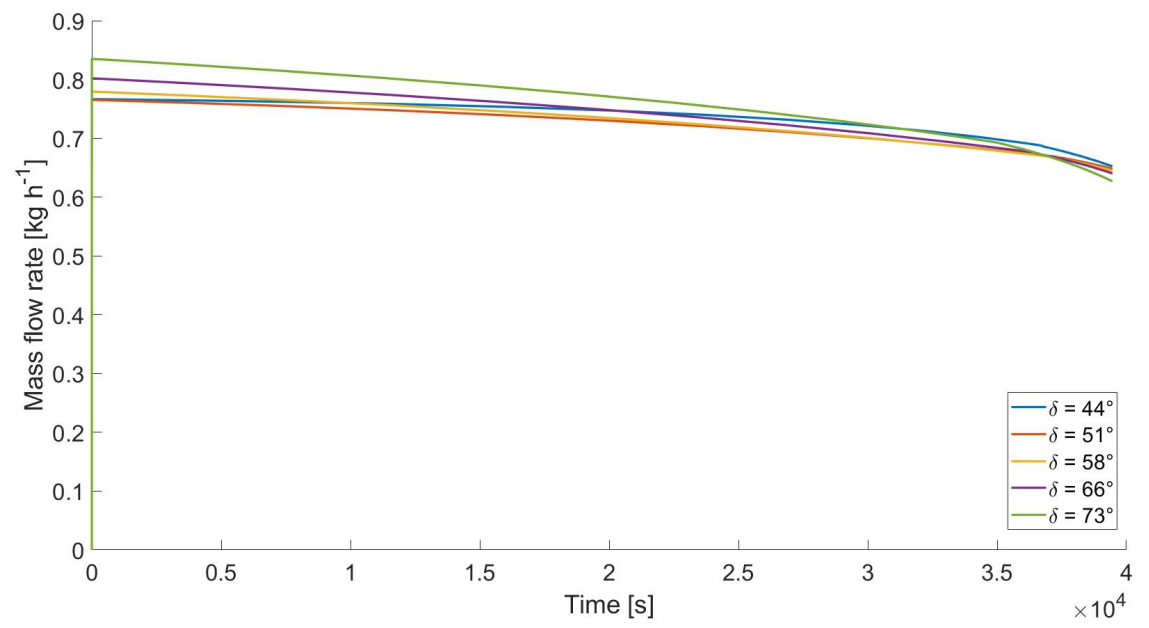

Figure 10: Impact of the effective angle of friction $\delta$ on the predicted feed rate using K-Tron KT20, microcrystalline cellulose Avicel PH 101, $7.71 \mathrm{rpm}$. 


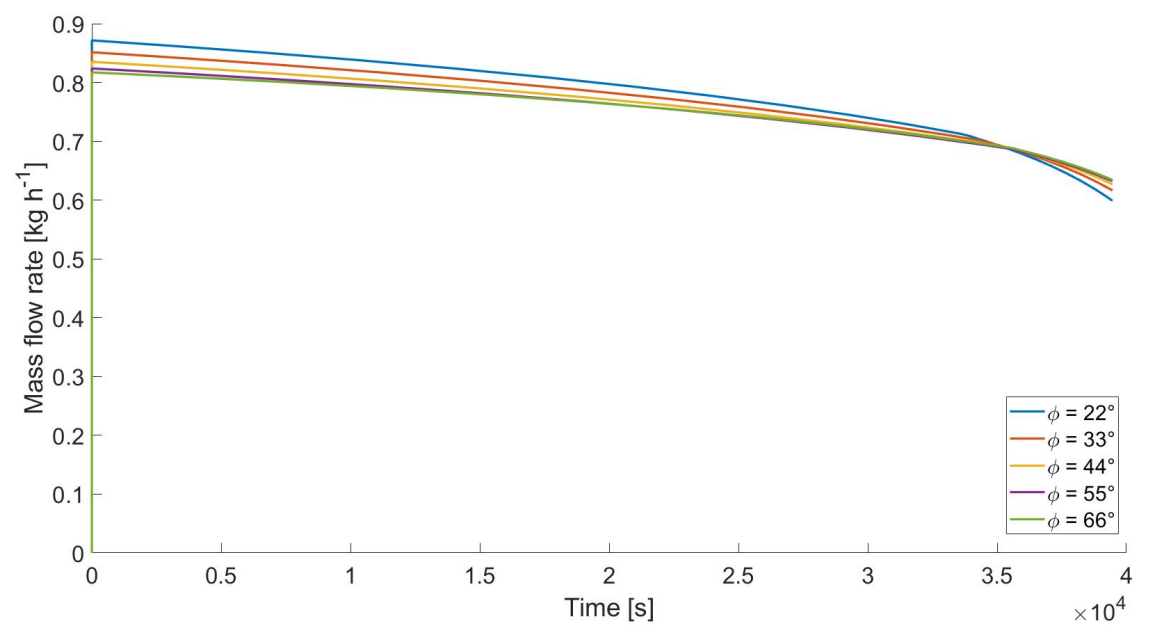

Figure 11: Impact of the wall friction angle $\phi$ on the predicted feed rate using K-Tron KT20, microcrystalline cellulose Avicel PH 101, 7.71 rpm.

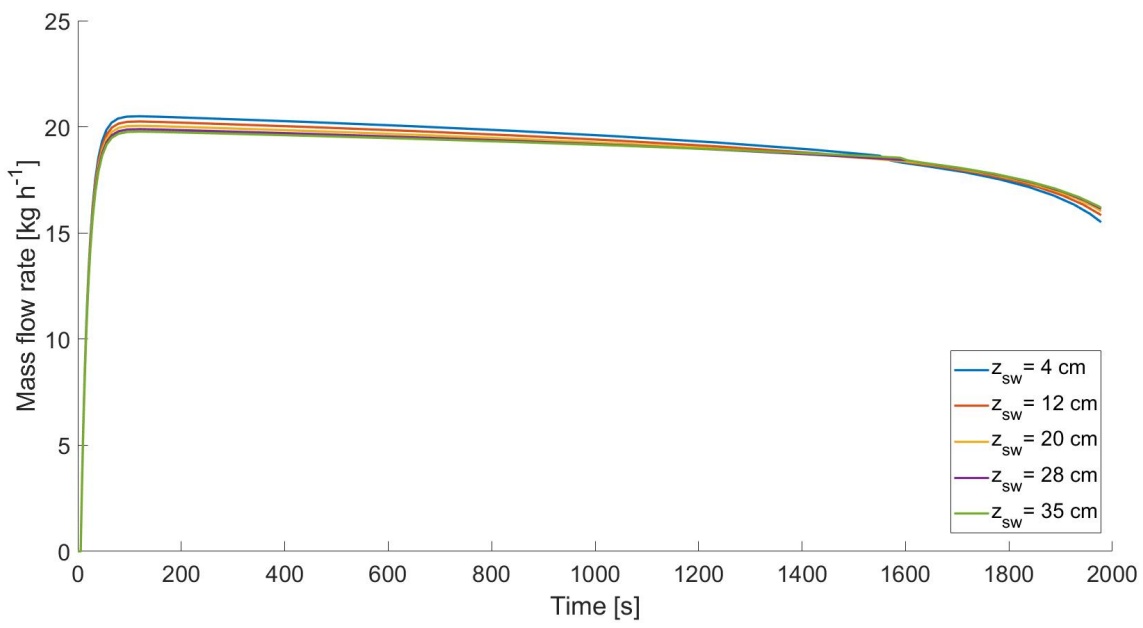

Figure 12: Impact of the switch point $\mathrm{z}_{\mathrm{SW}}$ on the predicted feed rate using K-Tron KT20, mannitol SD-100, $77.1 \mathrm{rpm}$. 


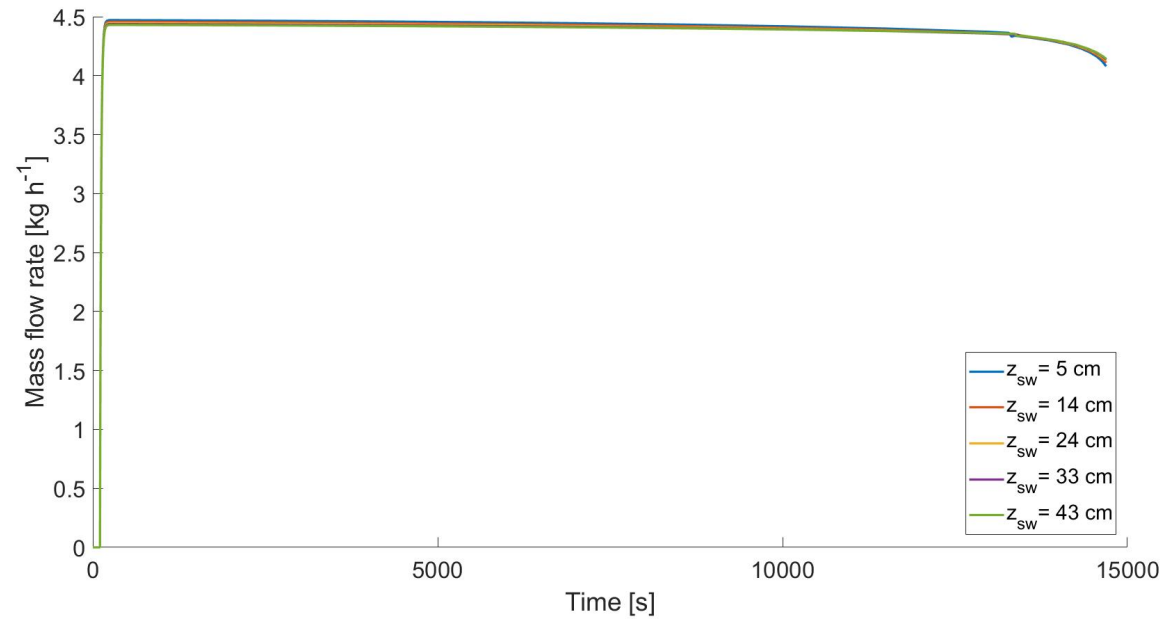

Figure 13: Impact of the switch point $\mathrm{z}_{\mathrm{sw}}$ on the predicted feed rate using K-Tron KT35, microcrystalline cellulose Avicel PH 102, 6.4 rpm. 


\section{${ }_{32}$ References}

(1) Waterman, K. C.; Macdonald, B. C. Package Selection for Moisture Protection for Solid, Oral Drug Products. J Pharma Sci 2010, 99, 4437 - 4452.

(2) Murikipudi, V.; Gupta, P.; Sihorkar, V. Efficient throughput method for hygroscopicity classification of active and inactive pharmaceutical ingredients by water vapor sorption analysis. Pharma Dev Technol 2013, 18, 348-358. 